\title{
Considerations for preparing prospective alcohol and drug counsellors
}

\section{Introduction}

The Substance Abuse and Mental Health Services Administration's (SAMHSA) National Survey on Drug Use and Health estimates that 23.5 million individuals age 12 years or older require treatment for an alcohol or a drug abuse problem. ${ }^{1}$ It is further estimated that an additional 11 million individuals meet the criteria for alcohol and drug treatment under the new provisions of the Affordable Health Care Act. ${ }^{2}$ However, of these individuals, only $11 \%$ will receive specialized treatment for an addictive disorder. ${ }^{1}$ The demand for alcohol and drug treatment has contributed to the need for professionals who specialize in alcohol and drug counselling. In fact, employment rates for alcohol and drug counsellors are expected to increase $27 \%$ by $2018 .^{3}$ This employment trend has led to discussions about the preparedness of alcohol and drug counsellors among behavioural health providers. ${ }^{4}$ The purpose of this brief report is to make recommendations for preparing prospective alcohol and drug counsellors.

The perceived recovery status is unique to the alcohol and drug profession, because many counsellors are themselves in recovery from substance abuse. ${ }^{5,6}$ The few studies conducted on this area of research have assessed perceived recovery status impacts on supervisory relationships, ${ }^{7,8}$ evidence-based practices, ${ }^{9}$ and competence. ${ }^{10,11}$ Simons et al. ${ }^{9}$ surveyed emerging counsellors and found that $53 \%$ of them were in recovery from substance abuse. Findings from this study suggest that recovering counsellors were more resistant to using evidence-based practices in alcohol and drug treatment compared to their counterparts. ${ }^{9}$ Subsequent studies indicate that less than one-third of alcohol and drug professionals identify themselves as in recovery. ${ }^{6,12,11} \mathrm{~A}$ recent study detected that professionals with a recovery identity were not as comfortable working with consumers diagnosed with depression, anxiety, and eating disorders, and were more likely to use twelve-step and faith-based approaches in treatment compared to those professionals without a recovery identity. ${ }^{11}$ Taken together, these findings indicate that professionals entering the alcohol and drug counselling field are less likely to identify as in recovery and those professionals who do identify as in recovery are more likely to use self-help approaches in treatment. Cross-training for professionals who do and do not identify as in recovery may be necessary to provide effective counselling for individuals diagnosed with an addictive disorder

Training for alcohol and drug counsellors has evolved from a peer-support model of recovery rooted in personal experience to a professional model of continuing care derived from treatment research. ${ }^{13}$ Although recovery models for alcohol and drug use have advanced, there is a great deal of variability in state staffing requirements and standards for certification/licensure as an alcohol and drug counsellor. ${ }^{2,14,15}$ West et al. ${ }^{16}$ Studied state standards for staffing regulations governing substance abuse treatment programs and found that few of them require a graduate degree to provide counselling or supervision. Kerwin, et al. ${ }^{17}$ Similarly detected that education, supervision, and training requirements for certification vary from state to state. Addiction knowledge and clinical supervision also varies in graduate counselling programs. ${ }^{18,4}$ The inconsistent training
Volume 3 Issue I - 2017

Lori Simons
Psychology Department, Widener University, USA

Correspondence: Lori Simons, Professor of Psychology, Psychology Department, Widener University, Chester, USA, Tel 610-499-4602, Fax 610-499-4603, Email lorgold@aol.com

Received: February 25, 2017 | Published: March 02, 2017

in counselling programs and addiction education may contribute to students being less prepared to enter the alcohol and drug workforce upon graduation. This discrepancy has contributed to concerns about the preparedness of alcohol and drug counselors. ${ }^{16,19}$

A national addiction counselling curriculum would address the concerns raised about inconsistencies in education, supervision and training. National and state boards, educators, and healthcare providers may want to consider developing an addiction counselling curriculum. Interdisciplinary or cross-disciplinary training should be provided so that alcohol and drug counsellors are comfortable and competent to work with different populations (i.e., adolescents) with varying problems (i.e., mental health issues). Alcohol and drug counsellors should also be trained to integrate techniques derived from both evidence-based treatment models (i.e., Medication Assisted Therapy) and twelve-step approaches. Evidence-based practices, as well as basic and advanced counselling models should be disseminated in undergraduate and graduate studies, continuing education training programs, and clinical supervision. It is reasonable to expect that professionals with a recovery identity may strongly identify with their work as an alcohol and drug counsellor; therefore, recovering perspectives should be incorporated into addiction education and clinical supervision. Simulation exercises and other experiential learning activities (i.e., attend a twelve-step meeting) could be infused to expand counsellors' perspective taking skills. Supervisors could also work with professionals who do and do not identify as in recovery so that they use blended or integrated counselling approaches in practice. Supervisors should assess how personal recovery experiences impact counselling. If these suggestions were to be utilized, then alcohol and drug counsellors with and without a recovery identity may be more prepared to practice.

\section{Acknowledgements}

None.

\section{Conflict of interest}

The author declares no conflict of interest.

\section{References}

1. Substance Abuse and Mental Health Services Administration (SAMHSA). Treatment Statistics. Retrieved from. 2015. 
2. Duryea DG, Calleja NG. Current expectations and existing deficits among addiction specialists. Alcoholism Treatment Quarterly. 2013;31(2):254 269

3. Bureau of Labour Statistics, Occupational Employment Statistics, Occupational Employment and Wages, May 2011, 21-1011. Substance Abuse and Behavioural Disorder Counsellors, USA, 2012.

4. Chandler N, Balkin RS, Perepiczka M. Perceived self-efficacy of licensed counsellors to provide substance abuse counselling. Journal of Addictions an Offender Counselling. 2011;32(1-2):29-42.

5. Culbreth JR. Substance abuse counsellors with and without a person history of chemical dependency: A review of the literature. Alcoholism Treatment Quarterly. 2000;18(2):67-82.

6. Curtis SL, Eby LT. Recovery at work: The relationship between social identity and commitment among substance abuse counsellors. J Subst Abuse Treat. 2010;39(3):248-254.

7. Culbeth JR, Borders LD. Perceptions of the supervisory relationships: Recovering and non-recovering substance abuse counsellors. Journal of Counselling and Development. 1999;77(3):330-338.

8. Culberth JR, Cooper JB. Factors impacting the development of substance abuse counselling supervisors. Journal of Addictions an Offender Counselling. 2008;29(1):22-35.

9. Simons L, Jacobucci R, Houston H. Novice, seasoned and veteran counsellors' views of addiction treatment manuals: The influence of counsellor characteristics on manual usefulness. J Psychoactive Drugs. 2006;38(4):483-491.

10. Greene CA. The perceived impact of recovery experience from alcoho and other drug addiction on learning during masters-level training. Alcoholism Treatment Quarterly. 2015;33(4):405-421.
11. Simons L, Haas D, Young J, et al. Exploring the professional development of alcohol and drug counsellors in the 21 st century: Who are they and what are their training needs? Journal of Alcohol and Drug Abuse. 2017.

12. Ogborne AC, Braun K, Schmidt G. Who works in addictions treatment services: Some results from an Ontario survey. Subst Use Misuse. 2001;36(13):1821-1837.

13. Reickmann T, Bergmann L, Rasplica C. Legislating clinical practice: Counsellor responses to an evidence-based practice mandate. $J$ Psychoactive Drugs. 2011;43(Sppl 7):27-39.

14. Miller G, Scarborough, Clark C, et al. The need for national credentialing standards for addiction counsellors. Journal of Addictions and Offender Counselling. 2010;30(2):50-57.

15. West PL, Hamm T. A study of clinical supervision techniques and training in substance abuse treatment. Journal of Addictions and Offender Counselling. 2012;33(2):66-81.

16. West PL, Mustaine BL, Wyrick B. State regulations and the ACA code of ethics and standards of practice: Oil and water for the substance abuse counsellor. Journal of Addictions and Offender Counselling. 1999;20(1):35-46.

17. Kerwin MLE, Walker Smith K, Kirby KC. Comparative analysis of state requirements for training of substance abuse \& mental health counsellors Journal of Substance Abuse Treatment. 2006;30(3):173-181.

18. Barnes EF, Rak E, Austin B, et al. Rehabilitation counsellor professional identity development in master's-level training programs: An exploratory study of potential influencing factors. Rehabilitation Education. 2012;26(2-3):185-198.

19. Mustaine BL, West PL, Wyrick BK. Substance abuse counsellor certification requirements: Is it time for a change? Journal of Addictions and Offender Counselling. 2003;23(2):99-107. 